\title{
The Role of Clinical Pharmacists in the Emergency Department
}

\author{
Brenna M. Farmer ${ }^{1} \cdot$ Bryan D. Hayes $^{2} \cdot$ Rama Rao $^{1} \cdot$ Natalija Farrell $^{3} \cdot$ Lewis Nelson $^{4}$
}

Received: 30 September 2017 / Accepted: 5 October 2017 / Published online: 26 October 2017

(C) American College of Medical Toxicology 2017

\section{Background}

Clinical pharmacists are integral to the care and safety of patients in the hospital, particularly in specialty and high-risk settings. Emergency departments (EDs) represent care environments that carry unique risks that may be addressed through the addition of clinical pharmacists specifically trained and/or experienced as an ED pharmacist. Adult and pediatric patients present with undifferentiated medical, neurological, traumatic, psychiatric, and surgical complaints $24 \mathrm{~h}$ a day, 7 days a week. Patients are generally unfamiliar to the emergency care providers, may be unable to communicate relevant medical information, and may require time-sensitive interventions. When present, ED crowding is associated with increased risk for medication errors [1-4]. Other factors that raise the risk for error include the expanding pharmacopeia, the increasing complexity of patient drug regimens $[5,6]$, and problems related to health information technology [7-9].

Despite the evidence supporting the role of pharmacists in the ED and support from national Emergency Medicine groups including the American College of Emergency Physicians [10], some hospitals rely on pharmacy personnel

Brenna M. Farmer

positionstatements@acmt.net

1 Division of Emergency Medicine, Weill Cornell Medical College of Cornell University, New York, NY, USA

2 Department of Pharmacy, Massachusetts General Hospital and Department of Emergency Medicine, Harvard Medical School, Boston, MA, USA

3 Department of Pharmacy, Boston Medical Center, Boston, MA, USA

4 Department of Emergency Medicine, Rutgers New Jersey Medical School, Newark, NJ, USA positioned outside the ED. Among EDs with dedicated pharmacists, few have 24-h coverage. This position statement by the American College of Medical Toxicology outlines the importance of dedicated pharmacists in the ED to improve care of adult and pediatric ED patients at all times.

Importance ED Pharmacists have demonstrated a positive impact on patient-specific outcome measures, timely medication administration, optimization of therapy, medication safety, and cost of care.

\section{Timely Medication Administration}

Published data demonstrate that the presence of an ED pharmacist is associated with a reduction in time to antibiotic administration for patients with sepsis [11-13], time to first analgesic in trauma patients [14], time to sedation and analgesia after rapid sequence intubation $[15,16]$, time to thrombolysis for patients with acute ischemic stroke [17], and door-to-balloon time for patients with acute myocardial infarction [18].

ED pharmacists also facilitate medication management for other time-sensitive situations such as cardiac resuscitations [19-22] and mass casualty events [23, 24]. This frees clinicians from retrieval and medication preparation, allowing them to remain at the bedside to render care.

\section{Optimization of Therapy}

Pharmacists are uniquely trained to verify medication orders for appropriateness, taking into account the indication, dosing intervals, and adjustment for patient-specific variables such as weight, organ function, allergies, and drug interactions. In addition, pharmacists can rapidly access documents regarding 
drug resistance patterns, current therapeutic guidelines, and local hospital antibiograms to improve selection of antimicrobial therapy [6, 12, 15, 25]. In some settings, ED pharmacist review of post-discharge cultures allows regimen modifications while also decreasing return visits and subsequent admissions [26-30]. In addition, ED pharmacists routinely make recommendations to optimize pharmacotherapy regimens particularly in regard to high-risk therapeutic classes such as central nervous system and cardiovascular medications, opioids, insulin, anticoagulants, and thrombolytics [31-33]. Pharmacists in the ED can review discharge prescriptions with patients and providers to ensure optimal therapy [34] and improved compliance for chronic illnesses such as asthma, chronic obstructive pulmonary disease, and congestive heart failure [35]. ED pharmacists also work collaboratively with emergency physicians and nurses, hospital pharmacists, medical toxicologists, and regional poison centers to manage patients with toxic exposures [36]. As part of the care team, pharmacists can recommend interventions that improve medication utilization and adherence to evidence-based medicine and national quality standards [31]. This has been particularly important with the increasing prevalence of critical drug shortages including antidotes [37, 38].

\section{Medication Safety}

ED pharmacists provide real-time decision support and order verification [39-41], and can intercept prescribing errors before patient harm occurs [33, 40, 42, 43]. Transitions of care are improved through medication reconciliation [44], thereby reducing errors and outpatient treatment failures [29, 34, 45-47]. Pharmacists may also recognize adverse drug events that another provider has not identified [48]. Finally, pharmacist-driven error reporting facilitates identification of safety deficits [49].

\section{Impact on Cost of Care}

The potential cost avoidance in reducing errors, eliminating antibiotic redundancies, meeting quality standards for reimbursement, improving patient satisfaction, and reducing ED revisits are important factors in the financial justification for dedicated ED staffing $[50,51]$.

\section{Summary}

The ED is a unique setting with a diverse and complex patient population presenting around the clock with urgent and emergent needs. Emergency physicians readily utilize and value the presence of ED pharmacists to aid in this care [10,
52-54]. We support 24-h staffing of emergency departments with dedicated ED pharmacists as part of the clinical care team. ACMT also supports studies to further define the impact and value of pharmacists in the ED and other areas of ED expansion such as urgent care and observation units.

Sources of Funding None.

\section{Compliance with Ethical Standards}

Conflict of Interest None.

Disclaimer The position of the American College of Medical Toxicology (ACMT) is as follows: clinical pharmacists are integral to the care and safety of emergency department (ED) patients. Emergency department pharmacists positively impact time to critical therapies, including antibiotics for sepsis and door-to-balloon time for acute myocardial infarction. Pharmacists optimize pharmacotherapy regimens involving high-risk therapeutic classes, such as thrombolytics. Clinical pharmacists improve patient safety by intercepting prescription errors and recognizing adverse drug events. The potential cost avoidance of reducing errors and meeting standards for reimbursement provides financial justification for dedicated ED clinical pharmacist staffing. We support 24-h staffing of emergency departments with dedicated ED pharmacists.

While individual practices may differ, this is the position of the American College of Medical Toxicology (ACMT) at the time written, after a review of the issue and pertinent literature.

\section{References}

1. Coil CJ, Flood JD, Beyeu BM, et al. The effect of emergency boarding on order completion. Ann Emerg Med. 2016;67:730-6.

2. Kulstad EB, Sikka R, Sweis S, et al. ED overcrowding is associated with an increased frequency of medication errors. Am J Emerg Med. 2010;28:340-9.

3. Manias E, Gerdtz MF, Weiland TJ, Collins M. Medication use across transition points from the emergency department: identifying factors associated with medication discrepancies. Ann Pharmacother. 2009;43(11):1755-64.

4. Marconi GP, Claudicus I. Impact of emergency department pharmacy on medication omission and delay. Pediatr Emerg Care. 2012;28:30-3.

5. Fairbanks RJ, Hays DP, Webster DF, et al. Clinical pharmacy services in an emergency department. Am J Health Syst Pharm. 2004;61:934-7.

6. Morganti KG, Bauhoff S, Blanchard JC, et al. The evolving role of emergency departments in the United States. Research report. Rand Corporation 2013. http://www.rand.org/content/dam/rand/pubs/ research_reports/RR200/RR280/RAND_RR280.pdf. Accessed 22 Mar 2015.

7. Ash JS, Berg M, Coiera E. Some unintended consequences of information technology in health care: the nature of patient care information system-related errors. J Am Med Inform Assoc. 2004;11(2):104-12.

8. Farley HL, Baumlin KM, Hamedani AG, et al. Quality and safety implications of emergency department information systems. Ann Emerg Med. 2013;62(4):399-407.

9. Koppel R, Metlay JP, Cohen A, et al. Role of computerized physician order entry systems in facilitating medication errors. JAMA. 2005;293(10):1197-203. 
10. American College of Emergency Physicians (ACEP). Clinical pharmacist services in the emergency department. Ann Emerg Med. 2015;66:444-5.

11. DeFrates SR, Weant KA, Seamon JP, et al. Emergency pharmacist impact on health care-associated pneumonia empiric therapy. J Pharm Pract. 2013;26:124-30.

12. Flynn JD, McConeghy KW, Flannery AH, et al. Utilization of pharmacist responders as a component of a multidisciplinary sepsis bundle. Ann Pharmacother. 2014;48:1145-51.

13. Moussavi K, Nikitenko V. Pharmacist impact on time to antibiotic administration in patients with sepsis in an ED. Am J Emerg Med. 2016;34(11):2117-21.

14. Montgomery K, Hall AB, Keriazes G. Pharmacist's impact on acute pain management during trauma resuscitation. J Trauma Nurs. 2015;22:87-90.

15. Amini A, Faucett EA, Watt JM, et al. Effect of pharmacist on timing of postintubation sedative and analgesic use in trauma resuscitations. Am J Health Syst Pharm. 2013;70:1513-7.

16. Johnson EG, Meier A, Shirakbari A, et al. Impact of rocuronium and succinylcholine on sedation initiation after rapid sequence intubation. J Emerg Med. 2015;49:43-9.

17. Montgomery K, Hall AB, Keriazes G. Impact of an emergency medicine pharmacist on time to thrombolysis in acute ischemic stroke. Am J Emerg Med. 2016;34(10):1997-9.

18. Acquisto NM, Hays DP, Fairbanks RJ, et al. The outcomes of emergency pharmacist participation during acute myocardial infarction. J Emerg Med. 2012;42:371-8.

19. Bond CA, Raehl CL. Clinical pharmacy services, pharmacy staffing, and hospital mortality rates. Pharmacotherapy. 2007;27:481-93.

20. Ernst AA, Weiss SJ, Sullivan A, et al. On-site pharmacists in the ED improve medical errors. Am J Emerg Med. 2012;30:717-25.

21. Groth CM, Acquisto NM. Pharmacists as members of the rapid response team. J Pharm Pract. 2016;29(2):116-20.

22. Porter E, Barcega B, Kim TY. Analysis of medication errors in simulated pediatric resuscitation by residents. West JEmerg Med. 2014;15:486-90.

23. Erickson K. An emergency department pharmacist's experience at the Boston Marathon. Am J Health Syst Pharm. 2013;70(19):1652,1654.

24. Sylvester KW, Rocchio MA, Belisle C, et al. Pharmacy response to the Boston Marathon bombings at a tertiary academic medical center. Ann Pharmacother. 2014;48(8):1082-5.

25. Weant KA, Baker SN. Emergency medicine pharmacists and sepsis management. J Pharm Pract. 2012;26:401-5.

26. Baker SN, Acquisto NM, Ashley ED, et al. Pharmacist-managed anticmicrobial stewardship program for patients discharged from the emergency department. J Pharm Pract. 2012;25:190-4.

27. Dumkow LE, Kenney RM, MacDonald NC, et al. Impact of a multidisciplinary culture follow-up program of antimicrobial therapy in the emergency department. Infect Dis Ther. 2014;3:45-53.

28. Miller K, McGraw MA, Tomsey A, et al. Pharmacist addition to post-ED visit review of discharge antimicrobial regimens. Am J Emerg Med. 2014;32:1270-4.

29. Randolph TC, Parker A, Meyer L, et al. Effect of a pharmacistmanaged culture review process on antimicrobial therapy in an emergency department. Am J Health Syst Pharm. 2011;68:916-9.

30. Van Devender EA. Optimizing antimicrobial therapy through a pharmacist-managed culture review process in the ED. Am J Emerg Med. 2014;32(9):1138.

31. Abu-Ramaileh AM, Shane R, Churchill W, et al. Evaluating and classifying pharmacists' quality interventions in the emergency department. Am J Health Syst Pharm. 2011;68:2271-5.

32. Bakhsh HT, Perona SJ, Shields WA, et al. Medication errors in psychiatric patients boarded in the emergency department. Int $\mathrm{J}$ Risk Saf Med. 2014;26:191-8.

33. Rothschild JM, Churchill W, Erickson A, et al. Medical errors recovered by emergency department pharmacists. Ann Emerg Med. 2010;55:513-21.
34. Cesarz JL, Steffenhagen AL, Svenson J, Hamedani AG. Emergency department discharge prescription interventions by emergency medicine pharmacists. Ann Emerg Med. 2013;61(2):209-14.

35. Hohner E, Ortmann M, Murtaza U, Chopra S, et al. Implementation of an emergency department-based clinical pharmacist transitionsof-care program. Am J Health Syst Pharm. 2016;73(15):1180-7.

36. Thomas MC, Acquisto NM, Shirk MB, Patanwala AEA. National survey of emergency pharmacy practice in the United States. Am J Health Syst Pharm. 2016;73:386-94.

37. Mazer-Amirshahi M, Hawley KL, Zocchi M, et al. Drug shortages: implications formedical toxicology. Clin Toxicol. 2015;53(6):519-24.

38. Rosoff PM, Patel KR, Scates A, Rhea G, Bush PW, Govert JA. Coping with critical drug shortages. Arch Intern Med. 2012;172(19):1494-6.

39. Patanwala AE, Hays DP, Sanders AB, et al. Severity and probability of harm of medication errors intercepted by an emergency department pharmacist. Int J Pharm Pract. 2011;19:358-62.

40. Patanwala AE, Sanders AB, Thomas MC, et al. A prospective, multicenter study of pharmacist activities resulting in medication error interception in the emergency department. Ann Emerg Med. 2012;59:369-73.

41. Sin B, Yee L, Claudio-Saez M, et al. Implementation of a 24-hour pharmacy service with prospective medication review in the emergency department. Hosp Pharm. 2015;50:134-8.

42. Brown JN, Barnes CL, Beasley B, et al. Effect of pharmacists on medication errors in an emergency department. Am J Health Syst Pharm. 2008;65:330-3.

43. Stasiak P, Afilalo M, Castelino T, et al. Detection and correction of prescription errors by an emergency department pharmacy service. CJEM. 2014;16:193-206.

44. Pevnick JM, Shane R, Schnipper JL. The problem with medication reconciliation. BMJ Qual Saf. 2016;25:726-30.

45. Ajdukovic M, Crook M, Angley C, et al. Pharmacist elicited medication histories in the emergency department: identifying patient groups at risk of medication misadventure. Pharm Pract. 2007;5(4):162-8.

46. Becerra-Camargo J, Martinez-Martinez F, Garcia-Jimenez EA. Multicenter, double-blind, randomised, controlled, parallel-group study of the effectiveness of a pharmacist-acquired medication history in an emergency department. BMC Health Serv Res. 2013;13:337.

47. Okere AN, Renier CM, Tomsche JJ. Evaluation of the influence of a pharmacist-led patient-centered medication therapy management and reconciliation service in collaboration with emergency department physicians. J Manag Care Spec Pharm. 2015;21:298-306.

48. Hohl CM, Zed PJ, Brubacher JR, Abu-Laban RB, et al. Do emergency physicians attribute drug-related emergency department visits to medication-related problems? Ann Emerg Med. 2010;55:493-502.

49. Weant KA, Humphries RL, Hite K, et al. Effect of emergency medicine pharmacists on medication-error reporting in an emergency department. Am J Health Syst Pharm. 2010;67:1851-5.

50. Hamblin S, Rumbaugh K, Miller R. Prevention of adverse drug events and cost savings associated with PharmD interventions in an academic level I trauma center: an evidence-based approach. J Trauma Acute Care Surg. 2012;73:1484-90.

51. Lada P, Delgado G Jr. Documentation of pharmacists' interventions in an emergency department and associated cost avoidance. Am J Health Syst Pharm. 2007;64:63-8.

52. Coralic Z, Kanzaria HK, Bero L, et al. Staff perceptions of an onsite clinical pharmacist program in an academic emergency department after one year. West J Emerg Med. 2014;15:205-10.

53. Fairbanks RJ, Hildebrand JM, Kolstee KE, et al. Medical and nursing staff highly value clinical pharmacists in the emergency department. Emerg Med J. 2007;24:716-9.

54. Nana B, Lee-Such S, Allen G. Initiation of an emergency department pharmacy program during economically challenging times. AJHP. 2012;69:1682-6. 